\title{
New species of squat lobsters of the genera Munida and Raymunida (Crustacea, Decapoda, Galatheidae) from Vanuatu and New Caledonia
}

\author{
Enrique MACPHERSON \\ Centro de Estudios Avanzados de Blanes (CSIC), \\ c. acc. Cala San Francesc 14, E-17300 Blanes (Spain) \\ macpherson@ceab.csic.es
}

KEY WORDS

Crustacea,

Decapoda,

Anomura,

Vanuatu,

New Caledonia,

Pacific Ocean, new species.
Macpherson E. 2009. - New species of squat lobsters of the genera Munida and Raymunida (Crustacea, Decapoda, Galatheidae) from Vanuatu and New Caledonia. Zoosystema 31 (3): 431-451.

\section{ABSTRACT}

Seven new species of the genera Munida Leach, 1820 (M. acola n. sp., M. clevai n. sp., M. jubata n. sp., M. mica n. sp., M. pauxilla n. sp. and M. squarrosa n. sp.) and Raymunida Macpherson \& Machordom, 2000 (R. vittata n. sp.) are described and illustrated from specimens collected during recent cruises carried out off Vanuatu. Munida acola n. sp. has the second abdominal somite unarmed, distal spines of the antennular peduncle unequal in size, and the P2-P4 dactyli with spines along the entire ventral border. Munida clevai n. sp. has small eyes, and spines on the anterior ridge of second abdominal somite. Munida jubata n. sp. is characterized by the presence of spines on the second abdominal somite, and unequally sized distal spines of antennular peduncle. Munida mica n. sp. and M. pauxilla $\mathrm{n}$. sp. have the frontal margin oblique, abdominal somites unarmed, and distal spines of antennular peduncle of different size. Munida squarrosa $\mathrm{n}$. sp. has the second abdominal segment with spines, and the distal half of the ventral border of P2-P4 dactyli unarmed. Raymunida vittata $\mathrm{n}$. sp. belongs to a group of species having the mesial spine of first antennal segment not reaching the end of the basal segment of antennular peduncle, and mero-carpal articulation of 44 nearly reaching the frontal margin of the carapace. 


\author{
MOTS CLÉS \\ Crustacea, \\ Decapoda, \\ Anomura, \\ Vanuatu, \\ Nouvelle-Calédonie, \\ océan Pacifique, \\ espèces nouvelles.
}

\begin{abstract}
RÉSUMÉ
Nouvelles espèces de galathéidés dans les genres Munida et Raymunida (Crustacea, Decapoda, Galatheidae) du Vanuatu et de Nouvelle-Calédonie.

Sept espèces nouvelles des genres Munida Leach, 1820 (M. acola n. sp., M. clevai n. sp., M. jubata n. sp., M. mica n. sp., M. pauxilla n. sp., and $M$. squarrosa n. sp.) et Raymunida Macpherson \& Machordom, 2000 ( $R$. vittata n. sp.) provenant du Vanuatu et de Nouvelle-Calédonie, sont décrites et illustrées. Munida acola n. sp. se caractérise par le second segment abdominal inerme, des épines distales de taille inégale sur les pédoncules antennulaires, et les dactyles des P2-P4 possédant des épines tout le long de leur bord ventral. Munida clevai n. sp. possède de petits yeux et des épines sur la ride antérieure du second segment abdominal. Munida jubata n. sp. est caractérisé par la présence d'épines sur le second segment abdominal et par la taille inégale des épines distales des pédoncules antennulaires. Munida mica n. sp. et M. pauxilla n. sp. ont le bord frontal de la carapace oblique, des segments abdominaux inermes et des épines distales des pédoncules antennulaires de taille inégale. Munida squarrosa n. sp. possède des épines sur le second segment abdominal et la moitié distale du bord ventral des dactyles des P2-P4 inerme. Raymunida vittata n. sp. appartient à un groupe d'espèces possédant l'épine mésiale du premier segment antennaire n'atteignant pas la fin du segment basal du pédoncule antennulaire, et l'articulation méro-carpal du P4 atteignant presque la marge frontale de la carapace.
\end{abstract}

\section{INTRODUCTION}

The South-West Pacific is considered as a "hot-spot" of squat lobsters diversity (Baba et al. 2008). This area has received great taxonomic attention in the last decades and numerous new species have been described as a result of sampling effort. The studies have covered many areas, e.g., New Caledonia (Macpherson 1994, 2006; Macpherson \& Baba 2006), Vanuatu (Macpherson 1999), Solomon Islands (Cabezas et al. 2009), eastern Australia (Baba 1994; Ahyong \& Poore 2004), New Zealand (Ahyong 2007). These works have shown a great diversity in the Galatheidae, mainly belonging to the genus Munida, and mostly concentrated along the continental shelf and slope and bathyal areas. The presence of the representatives of this genus in shallow waters is scarce and a more intense sampling effort in this area has been recommended (Baba et al. 2008).

Numerous representatives of the genera Agononida Baba \& de Saint Laurent, 1996, Munida Leach,
1820, Munidopsis Whiteaves, 1874, Paramunida Baba, 1988 and Raymunida Macpherson \& Machordom, 2000 were collected during the BOA 1 (November 2005) and SANTO 2006 (SeptemberOctober 2006) expeditions. For a narrative of the SANTO 2006 expedition, see Bouchet et al. (2008), and for a review of the geography and natural history of Santo, we refer to Bouchet et al. (in press). The SANTO expedition also worked in shallow waters $(<100 \mathrm{~m})$ and, in some of them, several interesting new species of Munida were found. In order to compare this material with other shallow water specimens, the samples from the LIFOU 2000 Expedition (Loyalty Islands, November 2000) were also studied. In this paper the new species found in these cruises are illustrated and described.

\section{MATERIAL AND METHODS}

The material examined is deposited in the collections of the Muséum national d'Histoire naturelle, Paris 
(MNHN). Measurements of specimens represent the postorbital carapace length. Terminology used mainly follows Baba \& de Saint Laurent (1996) and Baba (2005). Following Baba (2005) the terms flexor and extensor borders of articles are only used for the maxilipeds and dactylus of the walking legs.

\section{ABBREVIATIONS}

Mxp maxiliped;

ovig. ovigerous;

P1 pereiopod 1, cheliped;

P2-P4 pereiopods 2-4, first to third walking legs.

\section{SYSTEMATICS}

Family Galatheidae Samouelle, 1819

Genus Munida Leach, 1820

\section{Munida acola n. sp.}

(Fig. 1)

HoLOTYPE. - Loyalty Islands. LIFOU 2000, stn 1414 , $20^{\circ} 45.9^{\prime}$ S, $167^{\circ} 06.2^{\prime} \mathrm{E}, 4-7 \mathrm{~m}, 20 . X I .2000$, ơ $4.1 \mathrm{~mm}$ (MNHN-Ga 6692).

PARATYPES. - Loyalty Islands. LIFOU 2000, stn 1414 , $20^{\circ} 45.9^{\prime} \mathrm{S}, 167^{\circ} 06.2^{\prime} \mathrm{E}, 4-7 \mathrm{~m}, 20 . X I .2000,2$ ovig. 우 $3.7,3.8 \mathrm{~mm}, 1$ \% $2.9 \mathrm{~mm}$ (MNHN-Ga 6693). - Stn $1437,20^{\circ} 55.5^{\prime} \mathrm{S}, 167^{\circ} 04.2^{\prime} \mathrm{E}, 10-30 \mathrm{~m}, 10 . \mathrm{XI} .2000,10^{\circ}$ $3.0 \mathrm{~mm}$ (MNHN-Ga 6694). - Stn 1458, 2046.7's, $167^{\circ} 08.1^{\prime} \mathrm{E}, 17-24 \mathrm{~m}, 4 . X I .2000,3 \mathrm{o}^{7} \mathrm{o}^{\top 7} 2.8-3.1 \mathrm{~mm}$, 1 $3.0 \mathrm{~mm}$ (MNHN-Ga 6695).

ETYMOLOGY. - From the Greek, akolos, bit, in reference to the small size of the species.

Distribution. - Loyalty Islands, 4-30 m.

\section{DESCRIPTION}

Carapace 1.2 times longer than wide. Few secondary striae between main transverse ridges. Ridges with numerous very short non-iridescent setae and few simple iridescent setae. Intestinal region without scales. Gastric region with 9 or 10 epigastric spines. One parahepatic and one postcervical spine on each side. Frontal margins slightly oblique. Lateral margins slightly convex. Anteriormost spine situated at anterolateral angle, well developed, clearly not reaching level of sinus between rostrum and supraocular spines. Second spine anterior to cervical groove half length of preceding one. Branchial margins with five spines. Rostrum spiniform, about half length of remaining carapace, straight and horizontal. Supraocular spines reaching mid length of rostrum and not reaching distal corneal margins, slightly divergent, and directed slightly upwards (Fig. 1A).

Anterior part of fourth sternite slightly concave medially, contiguous to posterior margin of third sternite. Fourth thoracic sternite with a few small scaly striae; surface of fifth to seventh sternites smooth. Transverse ridges between fifth, sixth and seventh sternites obtuse, feebly granulated (Fig. 1B).

Abdominal somites unarmed. Second and third somites each with one transverse stria.

Eyes small, maximum corneal diameter about one-third distance between bases of anterolateral spines.

Basal segment of antennule (distal spines excluded) about one-fourth carapace length, overreaching end of corneae, distance between distal end of article and base of dorsolateral spine half length of remaining proximal portion; two distal spines, mesial spine clearly longer than lateral; two spines on lateral margin, proximal one short, located at mid length of segment, distal one long, nearly reaching end of distal spines (Fig. 1C). First segment of antennal peduncle with moderately long distomesial spine reaching end of second segment; second segment with two distal spines, mesial spine longer than lateral spine, reaching end of antennal peduncle; third segment unarmed (Fig. 1C).

Mxp3 ischium about 1.5 times length of merus measured along extensor margin, distoventrally bearing spine. Merus with one well-developed median spine on flexor margin, distal small; extensor distal margin with small spine (Fig. 1D).

P1 moderately squamous, with numerous plumose setae and few uniramous setae, denser along lateral and mesial margins. Palm slightly longer than fingers. Merus armed with some spines, strong spines on distal border, not overreaching proximal quarter of carpus. Carpus 1.5 times longer than high, with several spines on lateral sides. Palm with some spines along mesial and lateral sides. Fixed and movable fingers with row of spines along lateral and mesial margins, respectively, distally curving and crossing, ending in a sharp point (Fig. 1E). 


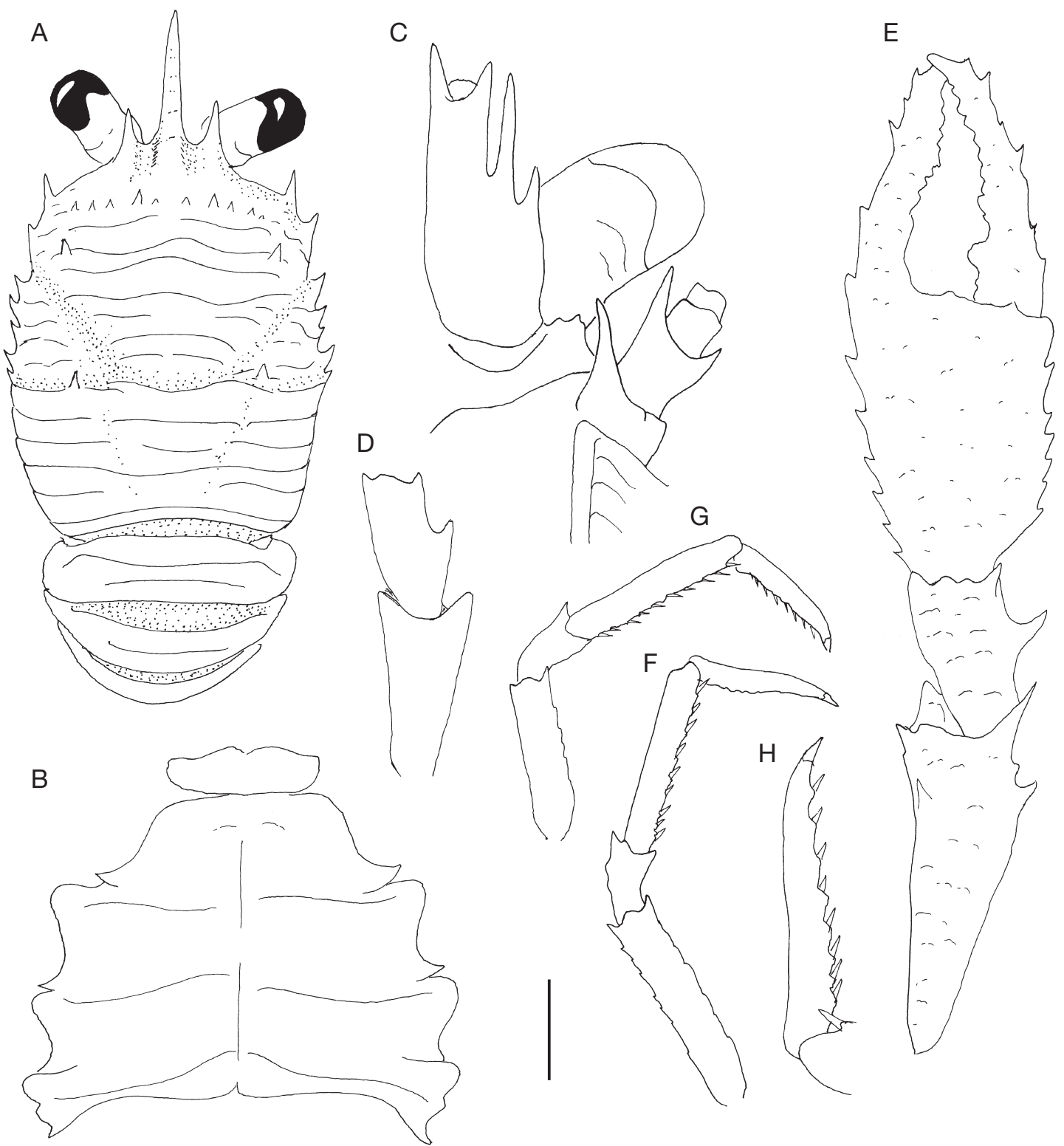

FIG. 1. - Munida acola n. sp., holotype, ơ $4.1 \mathrm{~mm}$ : A, carapace and abdomen, dorsal view; B, sternal plastron; C, cephalic region, showing antennular and antennal peduncles, ventral view; D, right Mxp3, lateral view; E, left P1, dorsal view; F, right P3, lateral view; G, right P4, lateral view; $\mathbf{H}$, dactylus of right P3, lateral view. Scale bar: A, E-G, 1 mm; B-D, H, 0.5 mm.

P2 lost in most specimens. P3 nearly twice carapace length; merus half carapace length, about 4.5 times as long as high, about 2.5 times carpus length and slightly longer than propodus; propodus about six times as long as high, about 1.5 times dactylus length (Fig. 1F). P3 merus with small spines on extensor border, increasing in size distally, ventral margin with one well-developed distal spine; carpus 
with several extensor spines and one distoventral spine; propodus with 9 or 10 movable ventral spines; dactylus slightly curving distally, with 9 movable spinules along entire flexor margin. P4 merus 0.8 length of $\mathrm{P} 3$ merus; merocarpal articulation reaching level of anterior end of cervical groove.

\section{REMARKS}

Munida acola $\mathrm{n}$. sp. belongs to the group of species having five spines on the branchial lateral margins of the carapace, smooth thoracic sternites, welldeveloped eyes, the P2-P4 dactyli with spines along the entire ventral border, and the second abdominal somite unarmed. The new species is closely related to M. leptitis Macpherson, 1994 from New Caledonia, Loyalty Islands, Indonesia, Wallis and Futuna and French Polynesia (Baba et al. 2008).

Munida acola n. sp. is easily distinguished from M. leptitis by the following:

- the P1 movable finger has a row of spines instead of one proximal and one distal spine on the mesial margin;

- the maximum corneal diameter is about onethird instead of half the distance between bases of anterolateral spines;

- the distomesial spine of the basal antennular peduncle is clearly longer instead of shorter than the distolateral spine.

\section{Munida clevai n. sp.}

(Fig. 2)

HOLOTYPE. - Vanuatu. BOA 1, stn 2452, $15^{\circ} 57.43^{\prime}$ ', 166 38.20'E, 1150-1273 m, 11.IX.2005, ovig. ㅇ $10.8 \mathrm{~mm}$ (MNHN-Ga 6696).

PARATYPES. - Vanuatu. BOA 1, stn 2452, 15²57.43'S, $166^{\circ} 38.20^{\prime} \mathrm{E}, 1150-1273 \mathrm{~m}, 11 . \mathrm{IX} .2005,7$ o $\mathrm{o}^{7} 6.5 \mathrm{~mm}$, $11.4 \mathrm{~mm}, 2$ ovig. 우 9.2, $11.0 \mathrm{~mm}, 4$ 우 9.6-11.8 mm (MNHN-Ga 6697).

Etymology. - The species is dedicated to Régis Cleva (MNHN), for his friendship and his invaluable help in taking care of decapod collections.

Distribution. — Vanuatu, between 1150-1273 m.

\section{DESCRIPTION}

Carapace slightly longer than wide. Few secondary striae between main transverse ridges. Ridges with very short non-iridescent setae. Few small scales on intestinal region. Gastric region with three pairs of epigastric spines. One parahepatic, one anterobranchial and one postcervical spine usually on each side. Frontal margins slightly oblique. Lateral margins slightly convex. First spine at anterolateral angle, long, reaching level of sinus between rostrum and supraocular spines. Second spine anterior to cervical groove half length of preceding one. Branchial margins with five spines. Rostrum spiniform, about 0.3 times length of remaining carapace, straight and horizontal. Supraocular spines barely reaching mid length of rostrum and slightly overreaching distal corneal margins, divergent, directed slightly upwards (Fig. 2A).

Lateral surfaces of thoracic sternites smooth. Fourth sternites smooth. Anterior margin of fourth sternite clearly narrower than third (Fig. 2B).

Second and third abdominal somites each with two transverse ridges, anterior ridge of second somite with row of 6-8 spines.

Eyes small, maximum corneal diameter one-fourth distance between bases of anterolateral spines.

Basal segment of antennule (distal spines excluded) about one-fourth carapace length, overreaching end of corneae, distance between distal end of segment and base of dorsolateral spine 0.3 length of remaining proximal portion; with two distal spines, mesial spine clearly shorter than lateral; two spines on lateral margin, proximal one short, located at mid length of segment, distal one long, nearly reaching end of distal spines (Fig. 2C). First segment of antennal peduncle with moderately long distomesial spine nearly reaching end of second segment; second segment with two distal spines, mesial spine longer than lateral spine, nearly reaching end of antennal peduncle; third segment unarmed (Fig. 2C).

Mxp3 ischium about 1.5 times length of merus measured along extensor margin, distoventrally bearing spine. Merus of third maxilliped with welldeveloped median spine on flexor margin, distal margin with very small spine or unarmed; extensor margin acute, without true spine (Fig. 2D).

P1 subequal in length, moderately squamous, with numerous uniramous and plumose setae denser on mesial borders of articles. Merus armed with some spines, spines stronger on distal border, not 
overreaching proximal quarter of carpus. Carpus twice as long as high, with several spines on dorsal and lateral sides. Palm nearly as long as fingers, with some spines along mesial, dorsal and lateral sides. Fingers unarmed, except one proximal spine on fixed finger and terminal spines on each finger, distally curving and crossing, ending in a sharp point (Fig. 2E).

P2 about twice carapace length; merus as long as carapace, about six times as long as high, about four times carpus length and 1.5 times as long as propodus; propodus about seven times as long as high, about 1.5 times dactylus length (Fig. 2F); end of carpus reaching or overreaching level of merocarpal articulation of P1. P2 merus with welldeveloped spines on extensor border, increasing in size distally, flexor margin with several spines and one long distal spine; carpus with several extensor spines and one distoventral spine; propodus with 7 or 8 movable flexor spines; dactylus slightly curving distally, with 9 movable spinules along entire flexor margin. P3 slightly shorter than P2; P4 shorter than P2 and P3. P4 merus half length of P2 merus; merocarpal articulation reaching level of anterior end of cervical groove.

\section{REMARKS}

Munida clevai $\mathrm{n}$. sp. belongs to the group of species having five spines on the branchial lateral margins of the carapace, smooth thoracic sternites, small eyes, and spines on the anterior ridge of the second abdominal somite. The new species is closely related to $M$. parvioculata Baba, 1982 from Japan and M. endeavourae Ayhong \& Poore, 2004, from southeastern Australia and Tasmania.

However, $M$. clevai $\mathrm{n}$. sp. is easily distinguished from $M$. parvioculata by several characters:

- the dorsal carapace surface is more squamate in $M$. parvioculata than in the new species;

- the P1-P4 are densely setose in M. parvioculata, whereas scarcely so in $M$. clevai n. sp.;

- the distomesial spine of the second segment of the antennal peduncle nearly reaches the end of the antennal peduncle in the new species, whereas this spine falls short of the end of the third segment as in $M$. parvioculata. Furthermore the third segment is unarmed in the new species, instead of bearing a distomesial spine in $M$. parvioculata;
- the P1 fixed finger bears a row of several spines along the lateral margin in $M$. parvioculata, whereas this margin has one proximal and one distal spine in the new species. Furtermore, the dorsal side of the carpus and the palm has more spinose in $M$. clevai n. sp. than in $M$. parvioculata;

- the P2 dactylus is about half as long as the propodus in $M$. parvioculata, whereas it is clearly more than half as long in the new species.

The new species is also distinguished from M. endeavourae by the following:

- the antennular basal segment is more elongate in M. endeavourae. The distance between the distal end of the segment and the base of the dorsolateral spine is 0.3 the length of the remaining proximal portion in $M$. clevai n. sp. This distance is more than 0.5 in $M$. endeavourae;

- the distomesial spine of the second segment of the antennal peduncle clearly exceeds the antennal peduncle in $M$. endeavourae, whereas this spine reaches at most the end of the antennal peduncle in $M$. clevai n. sp.;

- the dorsal and lateral spines of P1 fixed finger are stronger in $M$. clevai n. sp. than in $M$. endeavourae.

\section{Munida jubata n. sp.}

(Fig. 3)

Holotype. - Vanuatu. SANTO 2006, stn AT54, $15^{\circ} 32.1^{\prime} S, 167^{\circ} 14.1^{\prime} \mathrm{E}, 68-79 \mathrm{~m}, 2 . \mathrm{X} .2006$, ovig. ㅇ $3.9 \mathrm{~mm}$ (MNHN-Ga 6698).

Paratypes. - Vanuatu. SANTO 2006, stn AT54, $15^{\circ} 32.1^{\prime} \mathrm{S}, 167^{\circ} 14.1^{\prime} \mathrm{E}, 68-79 \mathrm{~m}, 2 . \mathrm{X} .2006,1$ ơ $^{\top} 3.0 \mathrm{~mm}$, 1 † $3.4 \mathrm{~mm}$ (MNHN-Ga 6699).

ETYMOLOGY. - From the Latin, juba, crest in reference to the dorsal ridge along the rostral spine.

Distribution. - Vanuatu, between 68 and $79 \mathrm{~m}$.

\section{DESCRIPTION}

Carapace slightly longer than wide. Transverse ridges usually interrupted in cardiac and branchial regions, with short, non-iridescent setae; some iridescent setae on each posterolateral angle of carapace and tuft of iridescent setae below first branchial spine. 


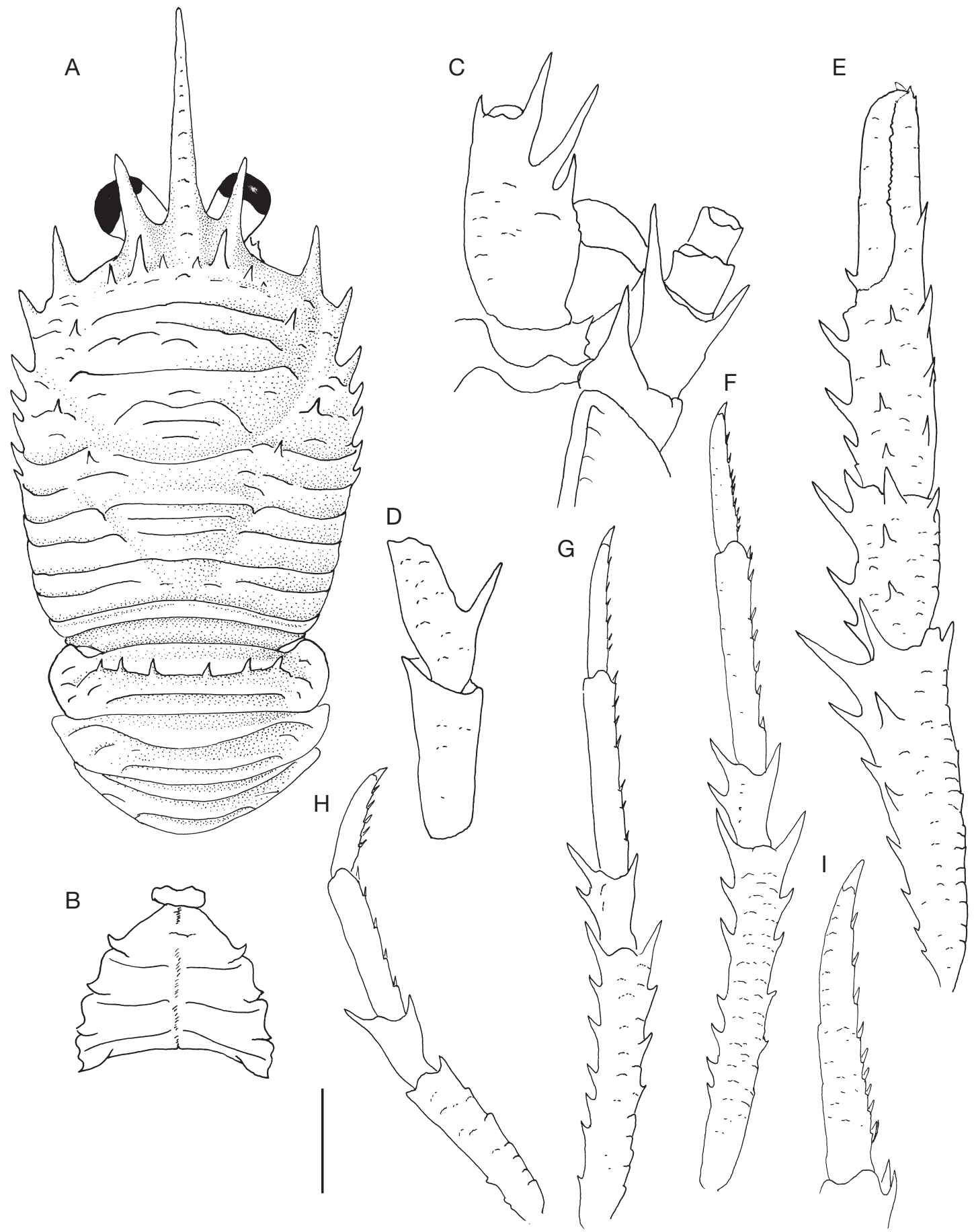

FIG. 2. - Munida clevai n. sp., holotype, ovig. $\$ 10.8$ mm: A, carapace and abdomen, dorsal view; B, sternal plastron; C, cephalic region, showing antennular and antennal peduncles, ventral view; $\mathbf{D}$, right $\mathrm{Mxp} 3$, lateral view; $\mathbf{E}$, right $\mathrm{P} 1$, dorsal view; $\mathbf{F}$, right $\mathrm{P} 2$, lateral view; G, right P3, lateral view; H, right P4, lateral view; I, dactylus of right P2, lateral view. Scale bar: A, B, E-H, 2 mm; C, D, I, 1 mm. 
Few secondary striae and scales between main striae. Intestinal region with short scales. Dorsal surface of carapace armed with 15 epigastric spines; one small hepatic and one postcervical spine on each side. Frontal margins moderately oblique. Lateral margins subparallel. First spine well developed, situated at anterolateral angle, far falling short of level of sinus between rostrum and supraocular spines. Second spine in front of cervical groove small, about one-fourth length of anterolateral spine. Branchial margins with 3 or 4 small spines. Rostrum spiniform, 0.4 length of remaining carapace, horizontal, dorsally carinated and slightly convex. Supraocular spines short, reaching mid length of rostrum and far falling short of end of corneae, subparallel, directed slightly upwards (Fig. 3A).

Fourth thoracic sternite smooth, with few short striae; other sternites smooth. Anterior part of fourth sternite concave medially, slightly narrower than third, contiguous to posterior median margin of third sternite (Fig. 3B).

Second and third abdominal somites each with two transverse ridges, anterior ridge of second and third somites with 6-8 and 2 spines, respectively.

Epistomic crest with jump near mouth.

Eyes large, maximum corneal diameter 0.4 times distance between bases of anterolateral spines.

Basal segment of antennule (distal spines excluded) about 0.4 carapace length, elongate, nearly 3 times longer than wide (excluding spines), reaching end of corneae, with 2 distal spines, mesial spine clearly shorter than lateral; 2 spines on lateral margin, proximal one short, located at mid length of segment, distal one long, not reaching end of segment (excluding spines) (Fig. 3C); distance between distal end of segment and base of dorsolateral spine 0.3 length of remaining proximal portion. First segment of antennal peduncle with short distomesial spine clearly not reaching end of second segment; second segment with 2 subequal distal spines, not exceeding end of third segment; third segment unarmed (Fig. 3C).

Mxp3 ischium twice length of merus measured along extensor margin, distoventrally bearing spine. Merus with 2 well-developed spines on flexor margin, distal smaller; extensor margin unarmed (Fig. 3D).
P1 subequal in length, squamous, with numerous uniramous iridescent setae and some plumose non-iridiscent setae denser on mesial and lateral borders of articles. Merus 2.5 times carpus length, armed with some spines, strongest spine on distal border, not reaching proximal fourth of carpus. Carpus 3.0-3.5 times as long as high, shorter than palm, several strong spines on mesial border and some small spines on dorsal side. Palm 1.3 times longer than fingers, with row of mesial spines, with some scattered small spines on dorsal side and one row of lateral spines continued with minute spines onto fixed finger and reaching tip. Movable finger with row of spines along entire mesial margin. Fingers distally curving and crossing, ending in sharp point, cutting edges with small teeth of various sizes (Fig. 3E).

P2 about 3 times carapace length, with numerous uniramous iridiscent setae and plumose noniridiscent setae along extensor margins; merus 1.1-1.3 times as long as carapace, about 8 times as long as high, 6 times carpus length and 1.6-1.8 times propodus length; propodus 9-10 times as long as high, and 1.1-1.4 times longer than dactylus (Fig. 3F). Dorsal border of merus with row of spines increasing in size distally, flexor margin with row of spines increasing in size distally. Carpus with distodorsal and distoventral spines; distal margin not reaching level of merocarpal articulation of P1. Propodus with 17-20 movable spinules along flexor margin. Dactylus long and slender, slightly curving distally, with 11 or 12 movable spinules along flexor margin, distal third unarmed (Fig. 3G). P3 slightly shorter than $\mathrm{P} 2$; spination of $\mathrm{P} 3$ similar to that of P2 (Fig. 3H). P4 length 0.8 times P2 length; merus 0.6-0.7 times length of P2 merus; margins of merus and carpus less spinose than those of $\mathrm{P} 2$ and P3 (Fig. 3I); merocarpal articulation reaching level of anterolateral spine of carapace.

\section{REMARKS}

The new species is closely related to $M$. parca Macpherson, 1996 from New Caledonia (Macpherson 1996). The two species have five spines on the lateral margin of the carapace behind cervical groove, eyes moderately large, the second abdominal segment with spines, the lateral parts of the posterior 


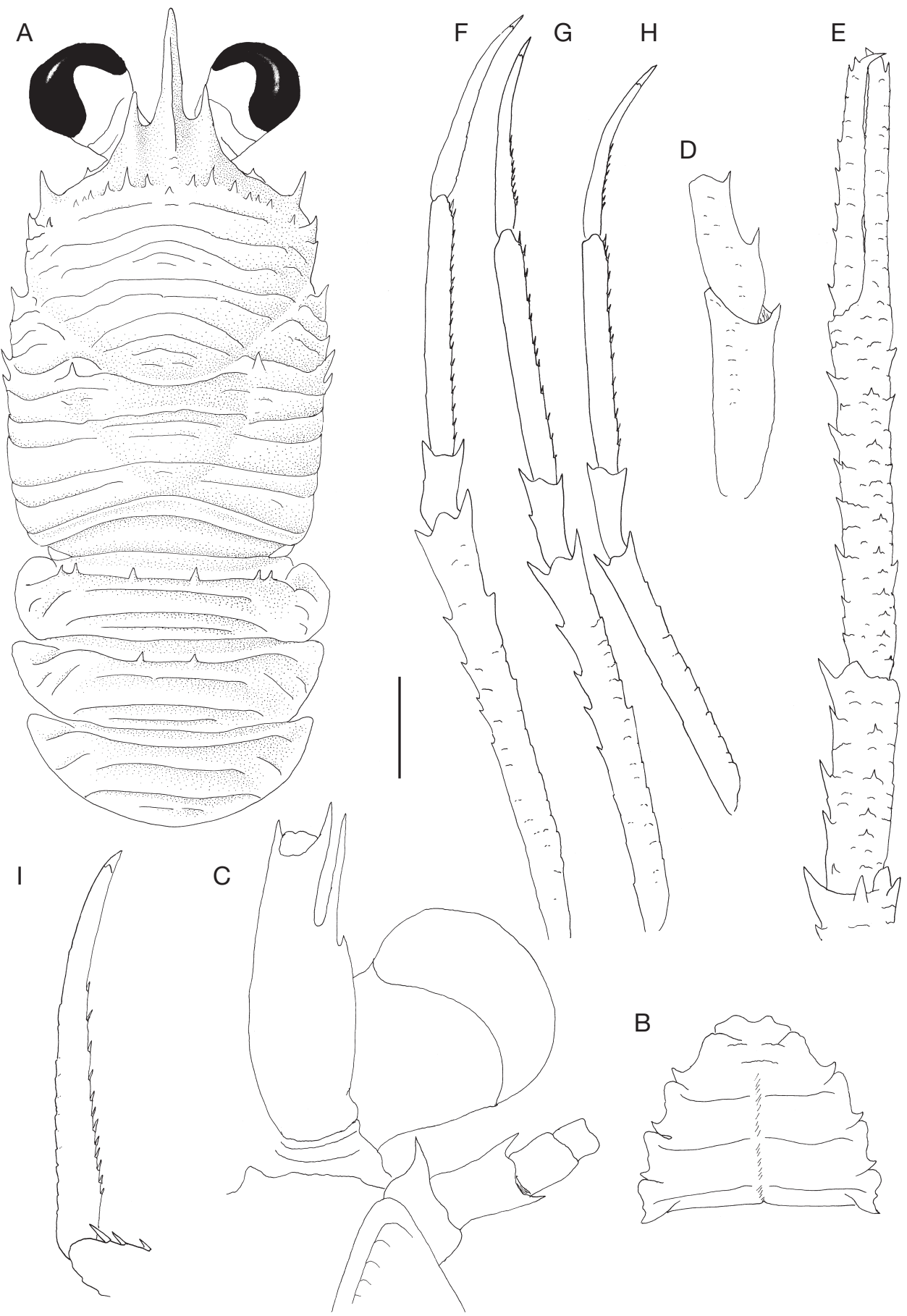

FIG. 3. - Munida jubata n. sp., holotype, ovig. ㅇ $3.9 \mathrm{~mm}$ : A, carapace and abdomen, dorsal view; B, sternal plastron; C, cephalic region, showing antennular and antennal peduncles, ventral view; $\mathbf{D}$, right $\mathrm{Mxp3}$, lateral view; $\mathbf{E}$, right $\mathrm{P} 1$, dorsal view; $\mathbf{F}$, right $\mathrm{P} 2$, lateral view; G, right P3, lateral view; H, right P4, lateral view; I, dactylus of right P2, lateral view. Scale bar: A, B, E-H, $1 \mathrm{~mm} ; \mathrm{C}, \mathrm{D}, \mathrm{I}, 0.5 \mathrm{~mm}$. 
thoracic sternites without granules, the rostrum spiniform, the epistomal crest without a jump near the mouth, the distomesial spine of basal antennular segment clearly shorter than the distolateral, and the distomesial spine of the basal antennal article nearly reaching the end of the third article. The two species are distinguished by the following characters:

- the P1 is clearly longer in the new species than in $M$. parca. In the new species it is about 4.5 times the carapace length, whereas this ratio is about 2.5 times in $M$. parca. The carpus is nearly 2.5 times longer than broad in $M$. parca, whereas it is 4 times longer in the new species;

- the walking legs (P2-P4) are longer in M. parca. The $\mathrm{P} 2$ is about 3 times the carapace length in the new species, instead of being slightly more than 2 times as in $M$. parca. Furthermore, the P2 merus is nearly as long as the carapace in $M$. parca, instead of being longer as in M. jubatan. sp. Furthermore, the merocarpal articulation ends at level of the anterolateral spine of the carapace in the new species, whereas this articulation slightly exceeds the level of the anterior branch of the cervical groove in $M$. parca.

\section{Munida mica n. sp.}

(Fig. 4)

HolotyPe. - Vanuatu. SANTO 2006, stn AT13, $15^{\circ} 27.8^{\prime} \mathrm{S}, 167^{\circ} 15.7^{\prime} \mathrm{E}, 146-153 \mathrm{~m}, 19 . \mathrm{IX} .2006$, ơ $3.6 \mathrm{~mm}$ (MNHN-Ga 6700).

PARATYPES. - Vanuatu. SANTO 2006, stn AT13, $15^{\circ} 27.8^{\prime} \mathrm{S}, 167^{\circ} 15.7^{\prime} \mathrm{E}, 146-153 \mathrm{~m}, 19 . \mathrm{IX} .2006,2 \mathrm{o}^{\circ} \mathrm{o}^{\circ}$ $3.2,3.4 \mathrm{~mm}, 6$ ovig. 우 $3.8-5.0 \mathrm{~mm}, 2$ 우 $2.3,5.7 \mathrm{~mm}$ (MNHN-Ga 6701). - Stn EP32, 1536.6'S, 167\%02.0'E, 100 m, 14.X.2006, 1 \% 5.1 mm (MNHN-Ga 6702). Stn DB77, $15^{\circ} 27.9^{\prime} S, 167^{\circ} 14.7^{\prime} \mathrm{E}, 42-45$ m, 29.IX.2006, 1 ovig. ? $3.6 \mathrm{~mm}, 1$ ㅇ $2.7 \mathrm{~mm}$ (MNHN-Ga 6703).

Etymology. - From the Latin mica, bit, grain, in reference to the small size of the species.

Distribution. - Vanuatu, 42-153 m.

\section{DESCRIPTION}

Carapace 1.2 times longer than wide. Main transverse ridges usually not interrupted in cardiac and posterior branchial regions, with very short, non-iridescent setae, and some scattered long iridiscent setae. Few secondary striae between main ridges. Intestinal region without scales. Dorsal surface of carapace armed with 10 or 11 epigastric spines; usually one small parahepatic, one anterobranchial and one postcervical spine on each side. Frontal margins strongly oblique. Lateral margins slightly convex. First spine situated at anterolateral angle, clearly not reaching level of sinus between rostrum and supraocular spines. Second spine in front of cervical groove small, about 0.3 length of anterolateral spine. Branchial margins with 5 spines. Rostrum spiniform, 0.5-0.7 length of remaining carapace, horizontal. Supraocular spines well developed, reaching mid length of rostrum and not reaching end of corneae, subparallel, slightly directed upwards (Fig. 4A).

Fourth thoracic sternite smooth, with few short striae; other sternites smooth. Anterior part of fourth sternite, contiguous to posterior margin of third sternite (Fig. 4B).

Second and third abdominal somites each with two transverse ridges, anterior ridge unarmed.

Epistomic crest with jump near mouth.

Eyes large, maximum corneal diameter about half distance between bases of anterolateral spines.

Basal segment of antennule (distal spines excluded) about 0.4 carapace length, elongate, about 2.5 times longer than wide (excluding spines), reaching end of corneae, with 2 distal spines, mesial spine slightly longer than lateral; 2 spines on lateral margin, proximal one short, located distal to mid length of segment, distal one long, reaching end of distal spines (Fig. 4C); distance between distal end of segment and base of dorsolateral spine 0.4 length of remaining proximal portion. First segment of antennal peduncle with distomesial spine reaching end of second segment; second segment with 2 distal spines, mesial spine slightly longer than lateral spine, slightly exceeding end of third segment; third segment unarmed (Fig. 4C).

Mxp3 ischium about 1.5 times length of merus measured along extensor margin, distoventrally bearing spine. Merus with 2 spines on flexor margin, distal smaller; extensor margin with distal spine (Fig. 4D).

P1 subequal in length, 1.8-2.8 times carapace length, squamous, with numerous uniramous iridescent setae and plumose non-iridiscent setae denser on 


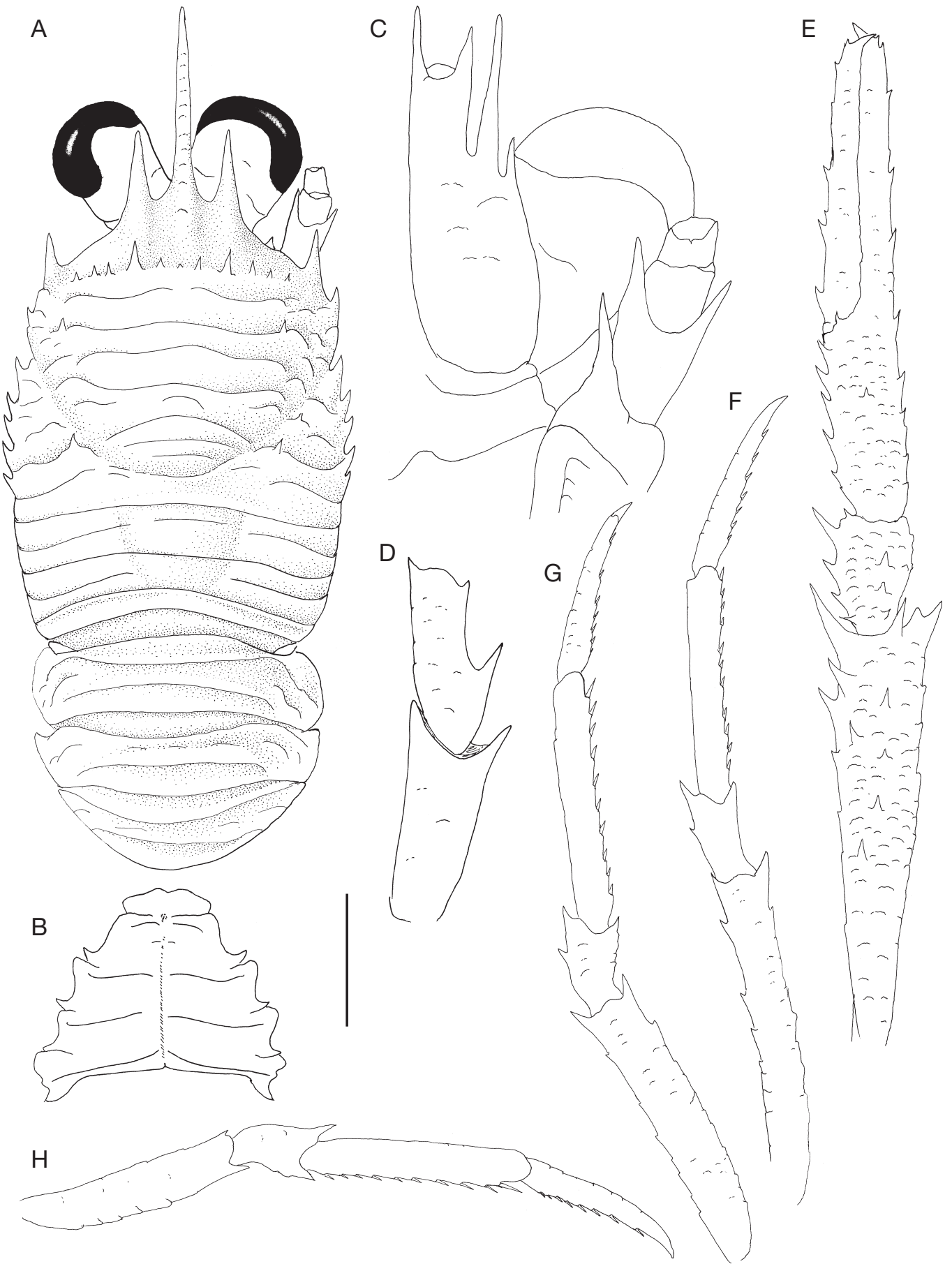

FIG. 4. - Munida mica n. sp., holotype, o $3.6 \mathrm{~mm}$ : A, carapace and abdomen, dorsal view; B, sternal plastron; C, cephalic region, showing antennular and antennal peduncles, ventral view; D, right Mxp3, lateral view; E, right P1, dorsal view; F, right P2, lateral view; G, right P3, lateral view; H, right P4, lateral view. Scale bar: A, B, E-H, $1 \mathrm{~mm} ; \mathrm{C}, \mathrm{D}, 0.5 \mathrm{~mm}$. 
mesial and lateral borders of articles. Merus shorter than carapace length, 3-4 times carpus length, armed with some spines, strongest spine on distal border, nearly reaching proximal half of carpus. Carpus 1.41.7 times as long as high, shorter than palm, several strong spines on mesial border and some small spines on dorsal side. Palm shorter than fingers, with row of mesial spines, and some scattered small spines on dorsal side and one row of lateral spines continued onto fixed finger and reaching tip. Movable finger with spines along mesial margin. Fingers distally curving and crossing, ending in sharp point, cutting edges with small teeth of various sizes (Fig. 4E).

P2 about twice carapace length, with numerous uniramous iridiscent setae and plumose noniridiscent setae along extensor margin; merus 0.8 times as long as carapace, 6.0-6.5 times as long as high, 3.5-4.0 times carpus length and 1.5-1.7 times as long as propodus; propodus 6-7 times as long as high, and slightly longer than dactylus (Fig. 4F). Extensor border of merus with row of small spines increasing in size distally, flexor margin with few spines increasing in size distally. Carpus with 1 or 2 extensor spines and one distoventral spine; distal margin not reaching level of merocarpal articulation of P1. Propodus with 11 or 12 movable spinules along flexor margin. Dactylus slightly curving distally, with 7 movable spinules along flexor margin, ultimate spine slightly more remote from tip of dactylus than from penultimate spine (Fig. 4G). P3 slightly shorter than $\mathrm{P} 2$; spination of $\mathrm{P} 3$ similar to that of P2 (Fig. 4H). P4 length 0.8 times P2 length; merus 0.7 times length of $\mathrm{P} 2$ merus; spines along margins of merus and carpus less spinose than those of P2 and P3 (Fig. 4I); merocarpal articulation reaching level of end of cervical groove.

\section{Colour}

Ground colour of carapace and abdomen light orange; striae reddish; one red spot on each margin of anterobranchial region. Rostrum, supraocular and anterolateral spines orange. P1-P4 with white and red bands; P2-P4 dactylus whitish.

\section{REMARKS}

The new species is closely related to $M$. pauxilla n. sp. from Vanuatu and Loyalty Islands. Their relationships are discussed under the remarks of that species (see below).

\section{Munida pauxilla n. sp.}

(Fig. 5)

Holotype. - Vanuatu. SANTO 2006, stn DB16, $15^{\circ} 35.5^{\prime} \mathrm{S}, 167^{\circ} 15.8^{\prime} \mathrm{E}, 32-40 \mathrm{~m}, 14 . \mathrm{IX} .2006$, ovig. ㅇ $5.5 \mathrm{~mm}$ (MNHN-Ga 6704).

PARATYPES. - Loyalty Islands. LIFOU 2000, stn 1413, $20^{\circ} 55.3^{\prime} \mathrm{S}, 167^{\circ} 05.0^{\prime} \mathrm{E}, 3-10 \mathrm{~m}, 15-18,26$ and $27 . \mathrm{XI} .2000$, 7 o" o" 4.0-4.9 mm, 1 ovig. ㅇ $3.4 \mathrm{~mm}, 3$ 우 우 4.5-5.0 mm (MNHN-Ga 6705). - Stn 1414, 20 $45.9^{\prime} S, 167^{\circ} 06.2^{\prime} \mathrm{E}$, 4-7 m, 20.XI.2000, 2 o" o" 4.0, $4.3 \mathrm{~mm}, 3$ ovig. 우 4.0-7.0 mm, 8 ㅇ 3.5-6.5 mm (MNHN-Ga 6706). Stn $1415,20^{\circ} 47.1^{\prime} \mathrm{S}, 167^{\circ} 09.1^{\prime} \mathrm{E}, 3-7 \mathrm{~m}, 25 . \mathrm{XI} .2000$, 10 o $^{7}$ ơ $^{7}$ 2.8-5.2 mm, 5 ovig. 우 3.8-6.6 mm, 1 우 $3.6 \mathrm{~mm}$ (MNHN-Ga 6707). - Stn 1437, 20 $55.5^{\prime} \mathrm{S}$, $167^{\circ} 04.2^{\prime} \mathrm{E}, 10-30 \mathrm{~m}, 10 . \mathrm{XI} .2000,2 \mathrm{o}^{7} \mathrm{o}^{7} 3.9,4.5 \mathrm{~mm}$, 4 ovig. 우 4.3-5.4 mm (MNHN-Ga 6708). - Stn 1445, 2050.8'S, $167^{\circ} 09.7^{\prime} \mathrm{E}, 10-12 \mathrm{~m}, 16 . X \mathrm{XI} .2000$, 1 o $^{7} 3.8 \mathrm{~mm}, 1$ \% $5.2 \mathrm{~mm}$ (MNHN-Ga 6709). - Stn 1452 , $20^{\circ} 54.6^{\prime} \mathrm{S}, 167^{\circ} 02.1^{\prime} \mathrm{E}, 2-25 \mathrm{~m}, 20-22 . \mathrm{XI} .2000$, 1 ơ $5.4 \mathrm{~mm}, 2$ ovig. 우 3.3, $3.7 \mathrm{~mm}$ (MNHN-Ga 6710). - Stn $1455,20^{\circ} 56.8^{\prime} \mathrm{S}, 167^{\circ} 02.7^{\prime} \mathrm{E}, 15-20 \mathrm{~m}$, 25.XI.2000, 3 o o o 3.8-6.2 mm, 3 ovig. 우 3.3-6.4 mm, 6 우 3.2-5.7 mm (MNHN-Ga 6711).

Etymology. - From the Latin pauxillus, dim, in reference to the small size of the species.

Distribution. - Vanuatu, 32-42 m, Loyalty Islands, $2-30 \mathrm{~m}$.

\section{DESCRIPTION}

Carapace 1.2 times longer than wide. Main transverse ridges usually interrupted in cardiac regions, with very short, non-iridescent setae, and some scattered long iridiscent setae. Few secondary striae between main ridges. Intestinal region without scales. Dorsal surface of carapace armed with row of 9 or 10 epigastric spines and some scattered spines between this row and first main stria; one small hepatic, one parahepatic, 1 or 2 anterobranchial and one postcervical spine on each side. Frontal margins strongly oblique. Lateral margins slightly convex. First lateral spine well developed, situated on the frontal margin, mesial to anterolateral angle, clearly not reaching level of sinus between rostrum and supraocular spines. Second spine very small, third 

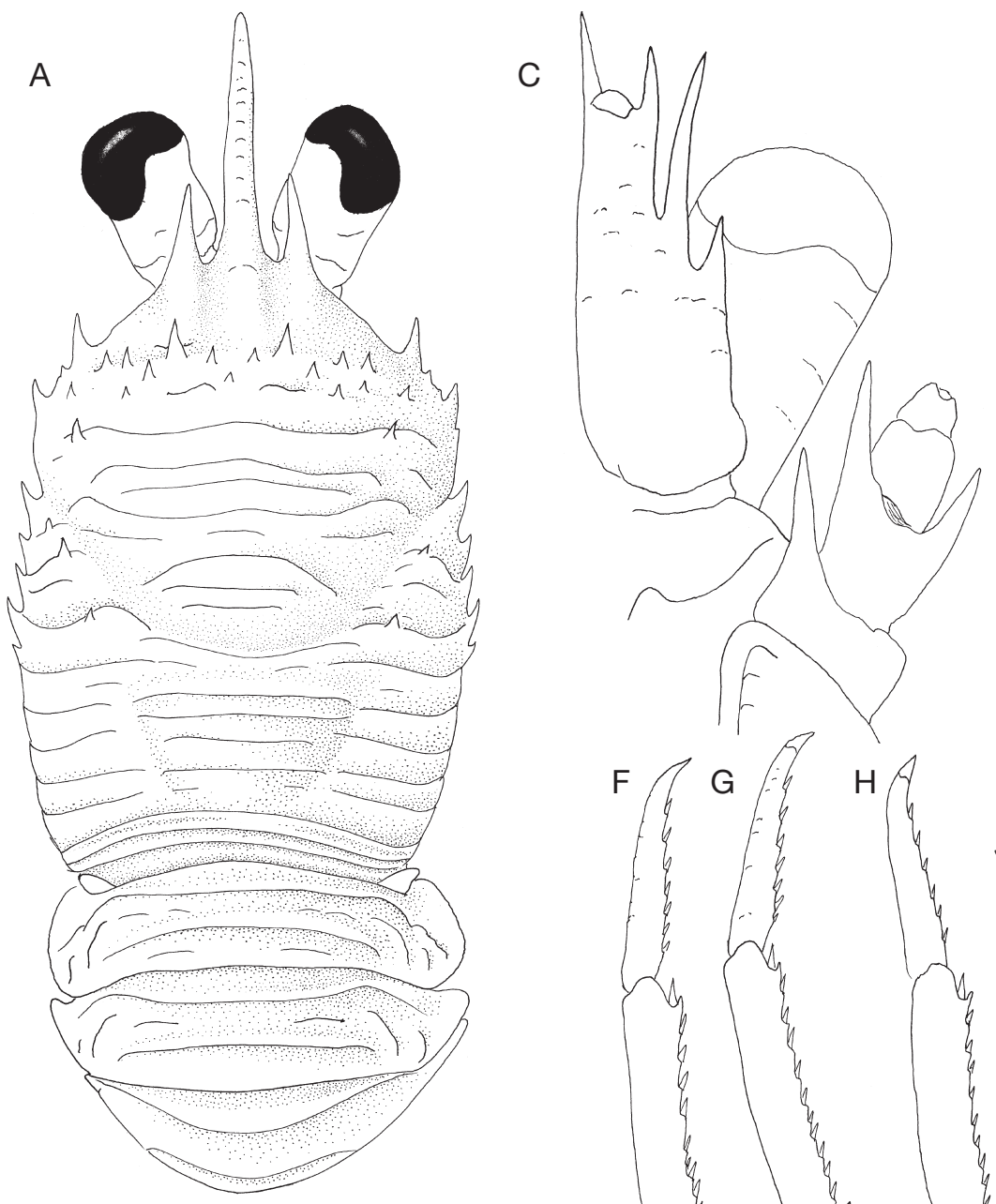

\section{E}

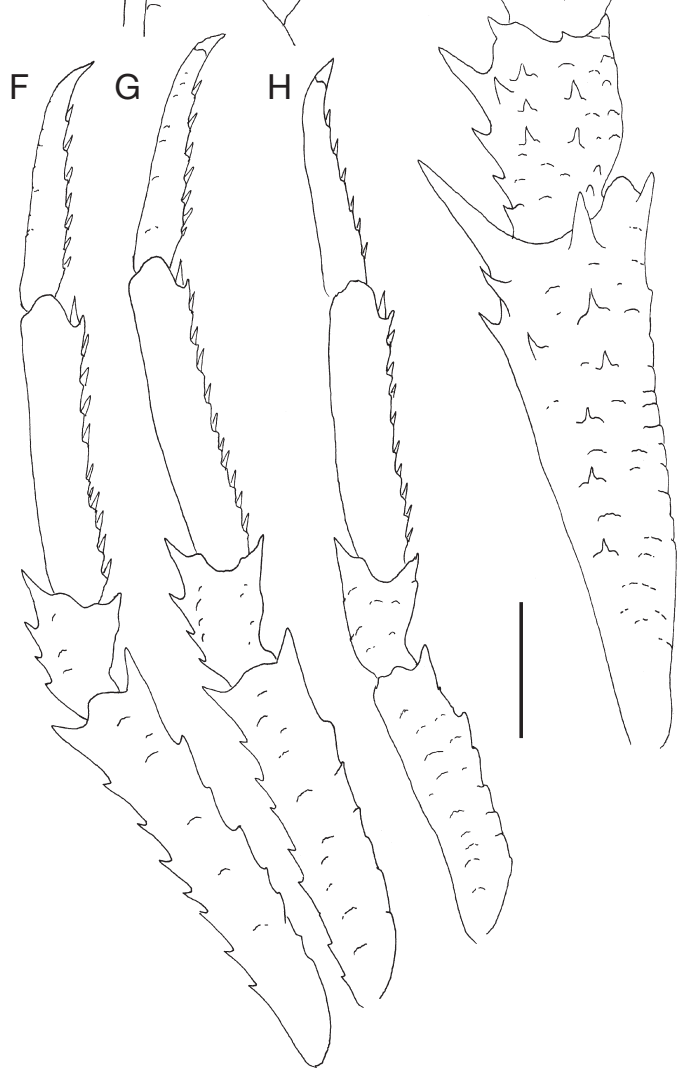

B
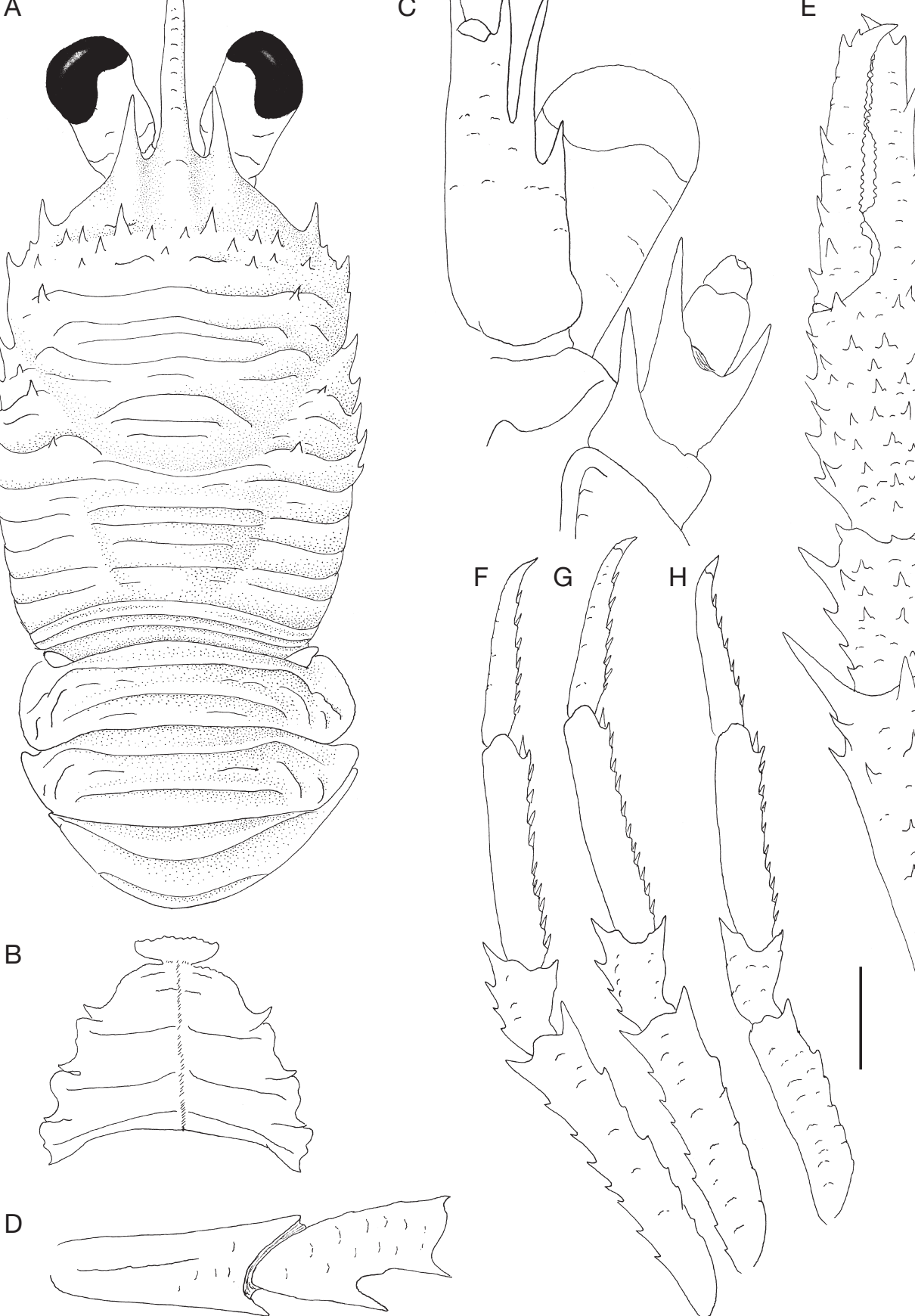

$\Lambda \Omega$ $\Lambda_{\Lambda} \hat{\Lambda} \Lambda_{i}$ $R \wedge \Lambda-j$ $\left\{\Lambda_{\wedge} \Omega_{1}\right\}$

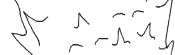
$r \sim$ $\int_{\mu} \sim \lambda$ $\int \Lambda \hat{n}$ $<\cdots \cdots$ $L_{-1}$ $\int \mu-1$

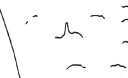


spine situated at anterolateral angle, about half length of first spine; fourth spine in front of cervical groove very small or absent. Branchial margins with 5 spines. Rostrum spiniform, horizontal. Supraocular spines well developed, reaching mid length of rostrum and not reaching end of corneae, subparallel, directed slightly upwards (Fig. 5A).

Fourth thoracic sternite smooth, with few short striae; other sternites smooth. Anterior part of fourth sternite slightly narrower than third, contiguous to median part of posterior margin of third sternite (Fig. 5B).

Abdominal somites unarmed. Second and third abdominal somites each with two transverse ridges.

Epistomic crest with jump near mouth.

Eyes large, maximum corneal diameter about 0.4 times distance between bases of anterolateral spines.

Basal segment of antennule (distal spines excluded) about 0.5 carapace length, elongate, about 2.5 times longer than wide (excluding spines), slightly exceeding end of corneae, with 2 distal spines, mesial spine longer than lateral; 2 spines on lateral margin, proximal one short, located at mid length of segment, distal one long, reaching end of distal spines (Fig. 5C); distance between distal end of segment and base of dorsolateral spine 0.3 length of remaining proximal portion. First segment of antennal peduncle with distomesial spine overreaching end of second segment; second segment with 2 long distal spines, mesial spine longer than lateral spine, slightly exceeding antennal peduncle; third segment unarmed (Fig. 5C).

Mxp3 ischium about 1.7 times length of merus measured along extensor margin, distoventrally bearing spine. Merus with 2 well-developed spines on flexor margin, distal smaller; extensor margin with distal spine (Fig. 5D).

P1 subequal in length, 2.5 times carapace length, squamous, with numerous uniramous iridescent setae and plumose non-iridiscent setae, denser on mesial and lateral borders of articles. Merus shorter than carapace, c. 2.5 times carpus length, armed with some spines, strongest spine on distal border, reaching proximal half of carpus. Carpus 1.5 times as long as high, shorter than palm, several strong spines on mesial border and some small spines on dorsal side. Palm shorter than fingers, with row of mesial spines, numerous scattered spines on dorsal side and one row of lateral spines continuing onto fixed finger and reaching tip. Movable finger with spines along mesial margin. Fingers distally curving and crossing, ending in sharp point, cutting edges with small teeth of various sizes, fixed finger with proximal process (Fig. 5E).

P2 nearly twice carapace length, with numerous uniramous iridiscent setae and plumose noniridiscent setae along extensor margins of articles; merus 4.5 times as long as high, 0.7 times as long as carapace, 3 times as long as carpus and 1.5 times as long as propodus; propodus 4.7 times as long as high, and slightly longer than dactylus (Fig. 5F). Extensor border of merus with row of small spines increasing in size distally, flexor margin with few spines increasing in size distally. Carpus with 4 dorsal spines and one distoventral spine; distal margin clearly not reaching level of merocarpal articulation of P1. Propodus with 11 movable spinules along flexor border. Dactylus slightly curving distally, with 7 movable spinules along flexor margin, ultimate spine more remote from tip of dactylus than from penultimate spine. P3 slightly shorter than $\mathrm{P} 2$; spination of $\mathrm{P} 3$ similar to that of P2 (Fig. 5G). P4 shorter than P2; merus 0.7 times length of $\mathrm{P} 2$; spines along margins of merus and carpus less spinose than those of $\mathrm{P} 2$ and $\mathrm{P} 3$; merocarpal articulation reaching level of anterior end of cervical groove.

\section{Colour}

Ground colour of carapace and abdomen reddish, with some scattered dark red spots. Rostrum, supraocular and anterolateral spines reddish. P1 merus with white distal band; fingers with proximal and distal white bands. P2-P4 whitish with some red spots.

\section{REMARKS}

The new species is closely related to $M$. olivarae Macpherson, 1994 from New Caledonia, Fiji and Tonga Islands and M. mica n. sp. (see above). These species have five spines on the branchial lateral margin, frontal margin oblique, eyes large, the abdominal somites unarmed, the lateral parts of 
the posterior thoracic sternites without granules, and the distomesial spine of the basal antennular segment clearly longer than the distolateral. Munida pauxilla n. sp. and M. mica n. sp. are distinguished from $M$. olivarae by the following characters: - the supraocular spines are longer in the new species, reaching instead of far falling short of the mid length of the rostrum;

- the distomesial spine of the first segment of antennal peduncle is longer, overreaching instead of nearly reaching the end of the second segment, and the distomesial spine of the second segment slightly exceeding the antennal peduncle, instead of terminating at the end of the third segment;

- the merocarpal articulation of the P4 reaches the level of the end of the cervical groove in $M$. pauxilla n. sp. and M. mica n. sp.;

Munida mica n. sp. and M. pauxilla n. sp. are distinguished by the following characters:

- the gastric region has spines other than epigastric in M. pauxilla n. sp. These spines are absent in M. mica n. sp.;

- the posterior margin of the third sternite is contiguous to the fourth sternite by the entire length in $M$. mica n. sp., whereas by only the median portion in $M$. pauxilla n. sp.;

- the dorsal side of the P1 palm has more spinose in M. pauxilla n. sp. than in M. mica n. sp.;

- the colour patterns are slightly different in both species. Munida pauxilla n. sp. has the ground colour of the carapace and the abdomen reddish, with some scattered dark red spots. Munida mica n. sp. has the ground colour of the carapace and the abdomen light orange; the striae are reddish, and with one red spot on each margin of anterobranchial region.

\section{Munida squarrosa n. sp.}

(Fig. 6)

Holotype. - Vanuatu. SANTO 2006, stn AT09, $15^{\circ} 41.5^{\prime} \mathrm{S}, 167^{\circ} 01.3^{\prime} \mathrm{E}, 481 \mathrm{~m}, 17 . I X .2006,1 \mathrm{o}^{\top 7} 10.6 \mathrm{~mm}$ (MNHN Ga 6712).

ETymology. - From the Latin, squarrosus, rough, in reference to the numerous scales in the pereiopods.

Distribution. - Vanuatu, $481 \mathrm{~m}$.

\section{DESCRIPTION}

Carapace 1.2 times longer than wide, slightly convex. Transverse ridges mostly interrupted in cardiac region, with dense short, non-iridescent setae; some uniramous iridescent setae along lateral margins of carapace. Intestinal region with one stria. Some scales and secondary striae between main striae. A row of 12 epigastric spines, one parahepatic, one hepatic and one postcervical spine on each side. Frontal margins nearly horizontal. Lateral margins feebly convex. First spine well developed, situated at anterolateral angle, not reaching level of sinus between rostrum and supraocular spines. Two small marginal spines in front of cervical groove one-third length of anterolateral one. Branchial margins with 5 small spines decreasing in size posteriorly. Rostrum spiniform, 0.6 times length of remaining carapace, slightly curved and horizontal. Supraocular spines short, not reaching mid length of rostrum, and clearly not reaching end of corneas, subparallel, directed upward (Fig. 6A).

Fourth thoracic sternite with a few small scales. Anterior part of fourth sternite narrower than third, slightly concave medially, contiguous to median posterior margin of third sternite. Transverse ridges between fifth, sixth and seventh sternites obtuse, feebly granulated (Fig. 6B).

Second and third abdominal somites each with four transverse ridges, anterior ridge of second somite with row of 9 spines.

Epistomic crest with hump near mouth.

Eyes moderately large, maximum corneal diameter nearly half distance between bases of anterolateral spines.

Basal segment of antennule (distal spines excluded), 0.3 carapace length, moderately elongate, slightly exceeding corneas, with 2 distal spines, mesial spine clearly shorter than lateral spine; 2 spines on lateral margin, proximal one short, located at mid length of segment, distal one long, nearly reaching end of distolateral spine (Fig. 6C); distance between distal end of article and base of dorsolateral spine 0.3 length of remaining proximal portion. First segment of antennal peduncle with distal spine on mesial margin, not reaching end of second segment; second segment with 2 distal spines, mesial spine clearly longer than lateral spine, overreaching 
end of antennal peduncle; third segment unarmed (Fig. 6C).

Mxp3 ischium nearly twice length of merus measured along extensor margin, distoventrally bearing spine. Merus bearing 2 spines on flexor margin, proximal spine prominent; extensor margin unarmed (Fig. 6D).

P1 squamate, 4.5 times carapace length, with numerous uniramous iridescent setae on mesial borders of articles. Merus longer than carapace, more than twice carpus length, armed with some spines, stronger spines on distal border, not reaching proximal fourth of carpus. Carpus 2.5 times longer than high, shorter than palm, with few spines on mesial, lateral and dorsal sides. Palm slightly longer than fingers, with row of spines along mesial and lateral borders, some small spines on dorsal side. Fingers distally curving and crossing, ending in a sharp point; fixed finger with some spines along entire border, 2 distal spines accommodating opposite spine of movable finger when closed; movable finger unarmed, except basal spine (Fig. 6E).

P2 twice carapace length; merus slightly shorter than carapace, about 7 times as long as high, 4 times carpus length and twice propodus length; propodus about 6 times as long as high, and 1.5 times longer than dactylus (Fig. 6F). Merus with row of some spines along extensor and flexor borders. Carpus with several spines and one distoventral spine; end of carpus nearly reaching mid length of merocarpal articulation of P1. Propodus with 11 movable spinules along flexor margin. Dactylus moderately long and slender, slightly curving distally, extensor margin slightly convex on proximal half, flexor margin with 7 movable spinules, unarmed on distal third. P3 similar in length and armature to P2; P3 merus shorter than $\mathrm{P} 2$ merus, and $\mathrm{P} 3$ propodus slightly longer than P2 propodus (Fig. 6H). P4 shorter than $\mathrm{P} 2$ and $\mathrm{P} 3$; $\mathrm{P} 4$ merus about 0.6 times P2 merus length; merocarpal articulation reaching level of anterior end of cervical groove.

\section{REMARKS}

The new species resembles $M$. mendagnai Cabezas, Macpherson \& Machordom, 2009 from Solomon Islands, in having five spines on the lateral margin of the carapace behind cervical groove, eyes large, the second abdominal segment with spines and some uninterrupted transverse striae, the lateral parts of the posterior thoracic sternites without granules, the rostrum spiniform, the distomesial spine of basal antennular segment clearly shorter than the distolateral, and the distal half of the flexor border of the P2-P4 dactyli unarmed. These species can be easily distinguished by the following characters:

- the distomesial spine of the second antennal segment clearly exceeds the antennal peduncle in the new species and reaches or slightly exceeds the distal margin of the third segment in $M$. mendagnai;

- the P1 is more elongate in the new species, having the merus clearly longer than the carapace, and the carpus 2.5 times longer than broad, whereas the merus is shorter than the carapace and the carpus is 1.4-1.7 times as long as broad in $M$. mendagnai.

\section{Genus Raymunida}

Macpherson \& Machordom, 2000

\section{Raymunida vittata n. sp.}

(Fig. 7)

HolotyPe. - Vanuatu. SANTO 2006, stn DB16, $15^{\circ} 35.5^{\prime} \mathrm{S}, 167^{\circ} 15.8^{\prime} \mathrm{E}, 32-40 \mathrm{~m}$, 14.IX.2006, ơ $6.6 \mathrm{~mm}$ (MNHN-Ga 6713).

Paratypes. - Vanuatu. SANTO 2006, stn AT41, 15³6.7-37.0'S, $167^{\circ} 02.7-02.8^{\prime} \mathrm{E}, 88-118 \mathrm{~m}$, 28.IX.2006, 2 ㅇ 4.4, 4.7 mm (MNHN-Ga 6714). - Stn AT56, $15^{\circ} 36.1^{\prime} \mathrm{S}, 167^{\circ} 01.3^{\prime} \mathrm{E}, 98-105 \mathrm{~m}, 2 . \mathrm{X} .2006,10^{7} 7.2 \mathrm{~mm}$, 1 ov. ㅇ $7.4 \mathrm{~mm}, 2$ 우 5.3, $5.7 \mathrm{~mm}$ (MNHN-Ga 6715). Stn EP32, 15 36.6'S, $167^{\circ} 02.0^{\prime} \mathrm{E}, 14 . X .2006,100 \mathrm{~m}$, 1 ov. ㅇ $6.8 \mathrm{~mm}$ (MNHN-Ga 6716).

ETymology. - From the Latin, vittatus, bound with a ribbon, in reference to the white and red bands in the chelipeds.

Distribution. - Vanuatu, 88-118 m.

\section{DESCRIPTION}

Carapace slightly longer than wide, bearing transverse ridges with very short, non-iridescent setae, and few long iridescent, simple setae; 2 main transverse striae on posterior part of carapace not interrupted on cardiac region. Gastric region with row of 10 


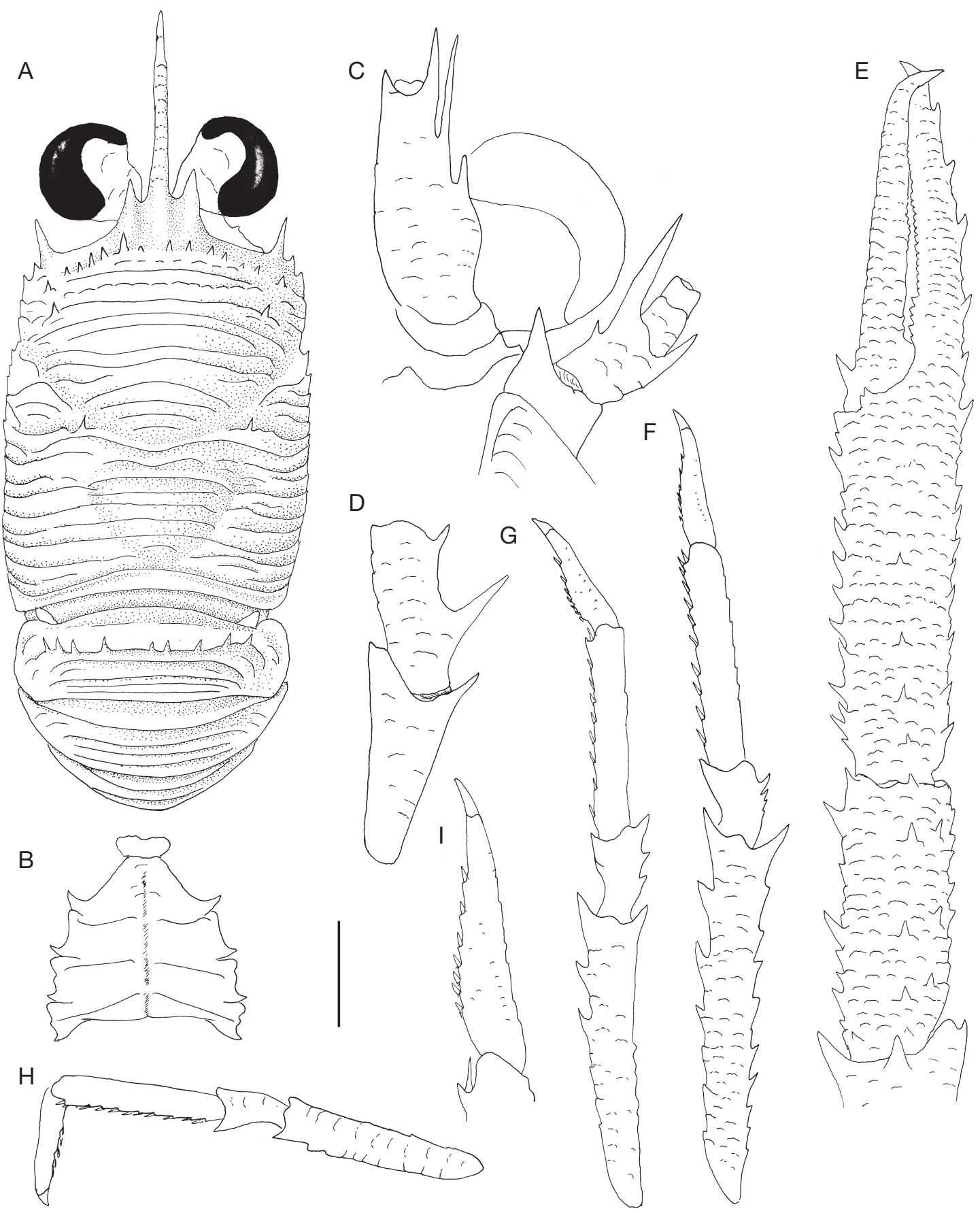

FIG. 6. - Munida squarrosa n. sp., holotype, o $10.6 \mathrm{~mm}$ : A, carapace and abdomen, dorsal view; B, sternal plastron; C, cephalic region, showing antennular and antennal peduncles, ventral view; D, right Mxp3, lateral view; E, right $\mathrm{P} 1$, dorsal view; $\mathbf{F}$, left $\mathrm{P} 2$, lateral view; G, left P3, lateral view; H, left P4, lateral view; I, dactylus of left P2, lateral view. Scale bar: A, B, E-H, 3 mm; C, D, I, 1.5 mm. 
epigastric spines. One parahepatic, 1-3 branchial anterior and 1 postcervical spine on each side. Frontal margins transverse, slightly convex at lateral end of orbit, small spine directly lateral to lateral limit of orbit. Lateral margins slightly convex. First spine, at anterolateral angle, clearly not reaching level of sinus between rostral and supraocular spines; marginal spine in front of cervical groove 0.3 length of anterolateral spine. Branchial margins with four spines; first spine as long as or slightly longer than anterolateral spine. Rostrum 0.6 times carapace length, slender, slightly curved upwards, supraocular spines clearly exceeding mid length of rostrum and end of corneas, feebly divergent and horizontal (Fig. 7A).

Thoracic sternites smooth; fourth sternite with few striae. Anterior part of fourth sternite slightly wider than third, contiguous to entire posterior margin of third somite (Fig. 7B).

Abdominal somites unarmed, with some long iridescent, simple setae. Second to fourth abdominal somites each with two transverse ridges.

Basal segment of antennule (distal spines excluded), 0.25 carapace length, reaching end of corneae, with 2 distal spines, mesial spine clearly shorter than lateral spine; 2 spines on lateral margin, proximal one short, located distal to mid length of segment, distal one long, reaching end of distolateral spine (Fig. 7C).

First segment of antennal peduncle with long distomesial spine exceeding antennal peduncle (only reaching end of peduncle in small specimens) and not clearly reaching end of basal segment of antennular peduncle (excluding distal spines); second segment with 2 distal spines, distomesial spine longer than distolateral spine, not overreaching antennal peduncle, 1 small spine at mid length of mesial border; penultimate segment unarmed.

Mxp3 merus with 2 long spines of subequal size on flexor border, and 1 distal spine on extensor margin (Fig. 7D).

P1 with long simple setae more numerous on mesial and lateral borders. Carpus twice as long as high, slightly shorter than palm; fingers 1.5 times palm length. Palm with several spines scattered on mesial and dorsal sides and 1 row of dorsolateral spines continued on to entire fixed finger; movable finger with spines on proximal half of mesial margin (Fig. 7E).

P2 about 2.5 times carapace length; merus slightly longer than carapace, 5.0-5.5 times as long as high, 3 times carpus length and 1.4 times propodus length; propodus 7-8 times as long as high and twice dactylus length. Merus with extensor marginal spines increasing in size distally, flexor margin with few distal spines. Carpus with some spines and 1 distoventral spine. Propodus with 4 or 5 movable spines along flexor margin (Fig. 7F). Dactylus short, curving distally, extensor margin slightly convex, flexor margin with 5 or 6 movable spinules along entire length. P3 slightly longer than P2. P4 shorter than second and third; length of merus $0.7-0.8$ that of $\mathrm{P} 2$; height greater than that of P2, 3.5-4.0 times as long as high, with row of laterodorsal spines in addition to dorsal row of spines (Fig. 7G). Merocarpal articulation of $\mathrm{P} 4$ leg nearly reaching frontal margin of carapace.

\section{Colour}

Ground colour of carapace and abdomen red; wide white band along each branchial margin of carapace; some white narrow transverse bands on dorsal surface of carapace. Rostrum, supraocular and anterolateral spines red. P1 with white and red bands, distal portion of fingers white. P2-P4 red, without white bands.

\section{REMARKS}

Raymunida vittata $\mathrm{n}$. sp. belongs to the group of species with the mesial spine of the first antennal segment not reaching the end of the basal segment of the antennular peduncle (excluding distal spines), the distomesial spine of the first antennal segment overreaching the antennal peduncle, and the merocarpal articulation of the $\mathrm{P} 4$ nearly reaching the frontal margin of the carapace. The new species is very close to $R$. lineata Osawa, 2005, from Japan. However, these two species are distinguished by the following differences:

- the second to fourth abdominal somites have a continuous transverse stria preceded by a median long stria in $R$. lineata. This median stria is absent, 


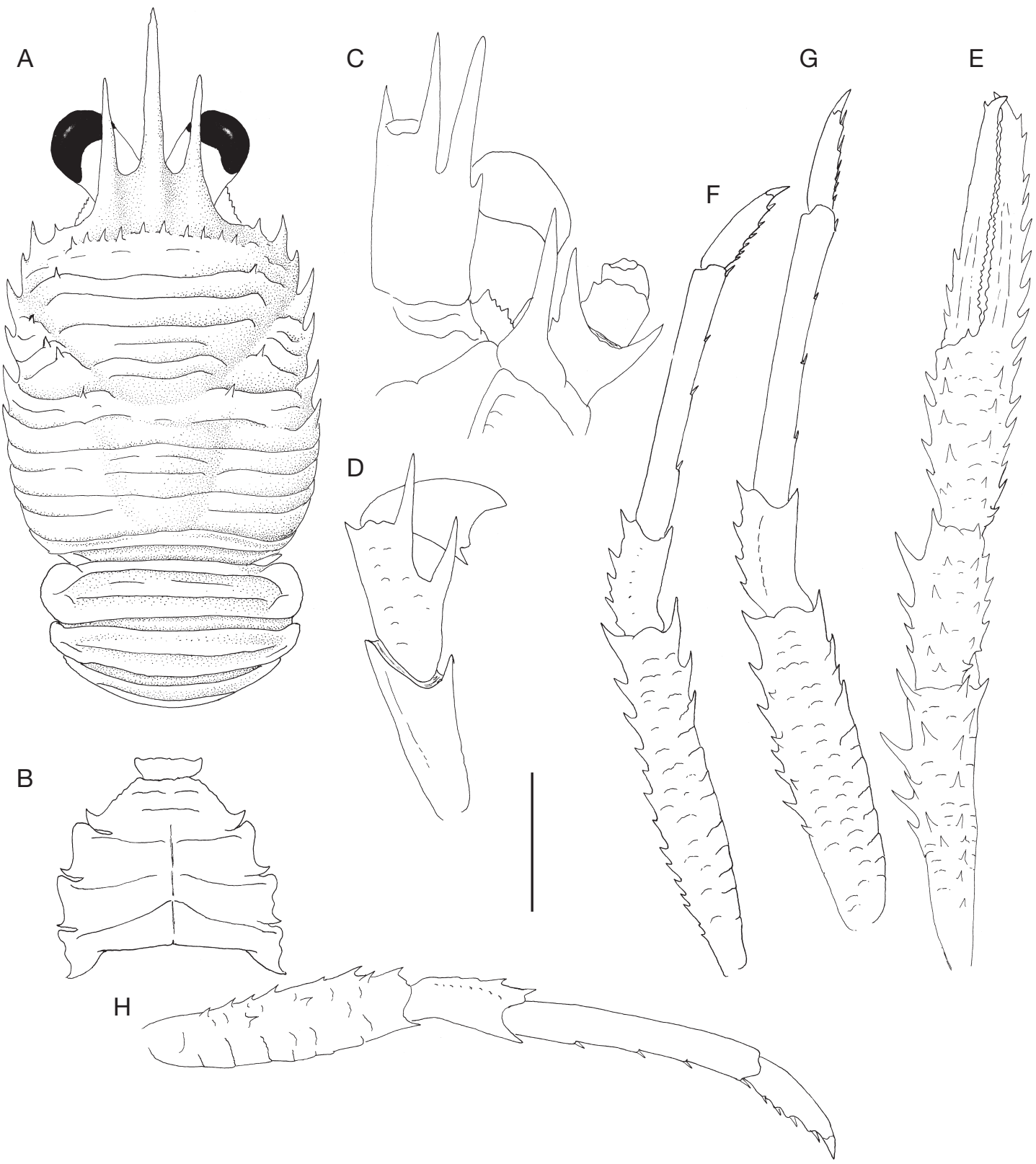

FIG. 7. - Raymunida vittata n. sp., holotype, ơ $6.6 \mathrm{~mm}$ : A, carapace and abdomen, dorsal view; B, sternal plastron; C, cephalic region, showing antennular and antennal peduncles, ventral view; D, right Mxp3, lateral view; E, right $\mathrm{P} 1$, dorsal view; F, right $\mathrm{P} 2$, lateral view; G, right P3, lateral view; $\mathbf{H}$, right P4, lateral view. Scale bar: $A, E-H, 2$ mm; B-D, 1 mm.

or with a pair of short striae in the new species; - the P1 fingers are longer in $R$. lineata than in $R$. vittata $\mathrm{n}$. sp., being twice instead of 1.5 times the length of the palm;
- the colour pattern of $R$. vittata n. sp., observed in all specimens examined, is also quite different from that of $R$. lineata: the white bands of the P1 are absent in $R$. lineata, present in $R$. vittata $n$. sp. 


\section{Acknowledgements}

The SANTO 2006 Expedition was organized by the Muséum national d'Histoire naturelle, Paris, Pro-Natura International (PNI), and Institut de Recherche pour le Développement (IRD). It operated under a permit granted to Philippe Bouchet (MNHN) by the Environment Unit of the Government of Vanuatu. The Marine Biodiversity part of the expedition, a part of Census of Marine Life's CReefs programme, was coordinated by Philippe Bouchet, Claude Payri and Bertrand Richer de Forges. The latter and Sarah Samadi collected on board of RV Alis many of the specimens reported here. Both the SANTO 2006 and LIFOU 2000 expeditions were supported by grants from the Total Foundation. I am greatly indebted to A. Crosnier for placing at my disposal these interesting specimens. Thanks are also due to K. Baba for improvements to the manuscript.

\section{REFERENCES}

Ahyong S. T. 2007. - Decapod Crustacea collected by the NORFANZ Expedition: Galatheidae and Polychelidae. Zootaxa 1593: 1-54.

Ahyong S. T. \& Poore G. C. B. 2004. — Deep-water Galatheidae (Crustacea: Decapoda: Anomura) from southern and eastern Australia. Zootaxa 472: 1-76.

BABA K. 1994. - Deep-sea galatheid crustaceans (Anomura: Galatheidae) collected by the 'Cidaris I' Expedition off central Queensland, Australia. Memoirs of the Queensland Museum 35: 1-21.

BABA K. 2005. - Deep-sea Chirostylid and Galatheid crustaceans (Decapoda. Anomura) from the IndoPacific, with a list of species. Galathea Report 20: 1-313.

Baba K. \& Saint Laurent M. DE 1996. - Crustacea Decapoda: revision of the genus Bathymunida Balss, 1914, and description of six new related genera (Galatheidae), in Crosnier A. (ed.), Résultats des campagnes MUSORSTOM, volume 15, Mémoires du Muséum national d'Histoire naturelle 168: 433-502.

Baba K., Macpherson E., Poore G. C. B., Ahyong S.T., Bermudez A., Cabezas P., Lin C. W., Nizinski M., Rodrigues C. \& SCHNABel K. E. 2008. - Catalogue of squat lobsters of the world (Crustacea: Decapoda: Anomura - families Chirostylidae, Galatheidae and Kiwaidae). Zootaxa 1905: 1-220.

Bouchet P., Le Guyader H. \& Pascal O. 2008. Des voyages de Cook à l'expédition Santo 2006: un renouveau des explorations naturalistes des îles du
Pacifique. Journal de la Société des Océanistes 126-127: 167-185.

Bouchet P., Le Guyader H. \& Pascal O. (eds) in press. - The Natural History of Santo. Patrimoines Naturels.

Cabezas P., Macpherson E. \& Machordom A. 2009. - Morphological and molecular description of new species of squat lobsters (Crustacea: Decapoda: Galatheidae) from the Solomon and Fiji Islands (SW Pacific). Zoological Journal of the Linnean Society 156 (3): 465-493.

MACPHERSON E. 1994. - Crustacea Decapoda: studies on the genus Munida Leach, 1820 (Galatheidae) in New Caledonian and adjacents waters with descriptions of 56 new species, in Crosnier A. (ed.), Résultats des campagnes MUSORSTOM, volume 12. Mémoires du Muséum national d'Histoire naturelle 161: 421-569.

MACPHERSON E. 1996. - Crustacea Decapoda: species of the genera Munida Leach, 1820 and Paramunida Baba, 1988 (Galatheidae) from the seas around the Wallis and Futuna Islands, in CROSNIER A. (ed.), Résultats des campagnes MUSORSTOM, volume 15. Mémoires du Muséum national d'Histoire naturelle 168: 387-421.

MACPHERSON E. 1999. - Crustacea Decapoda: species of the genera Agononida Baba \& de Saint Laurent, 1996 and Munida Leach, 1820 (Galatheidae) collected during the MUSORSTOM 8 cruise in Vanuatu, in CROSNIER A. (ed.), Résultats des campagnes MUSORSTOM, volume 20. Mémoires du Muséum national d'Histoire naturelle 180: 407-426.

MACPHERSON E. 2006. — New species and new occurrence of Galatheoidea (Crustacea, Decapoda) from New Caledonia. Zoosystema 28 (3): 669-681.

MACPHERSON E. \& BABA K. 2006. — New species and records of small galatheids (Crustacea, Decapoda, Galatheidae) from the southwest and central Pacific Ocean. Zoosystema 28 (2): 443-456.

MACPHERSON E. \& MACHORDOM A. 2000. — Raymunida, new genus (Decapoda: Anomura: Galatheidae) from the Indian and Pacific Oceans. Journal of Crustacean Biology 20: 253-258.

OsaWA M. 2005. - The identity of Raymunida elegantissima (Crustacea: Decapoda: Anomura: Galatheidae) and description of a closely related new species from Japan. Species Diversity 10: 85-104.

Samouelle G. 1819. - The Entomologists' Useful Compendium; or an Introduction to the Knowledge of British Insects, Comprising the Best Means of Obtaining and Preserving Them, and a Description of the Apparatus Generally Used; Together with the Genera of Linné, and Modern Methods of Arranging the Classes Crustacea, Myriapoda, Spiders, Mites and Insects, from their Affinities and Structure, According to the Views of Dr. Leach. Also an Explanation of the Terms Used in Entomology; a Calendar of the Times of Appearance and Usual Situations 
of Near 3,000 Species of British Insects; with Instructions for Collecting and Fitting up Objects for the Microscope. Thomas Boys, London, 496 p., 412 pls.
Whiteaves J. F. 1874. — On recent deep-sea dredging operations in the Gulf of stn Lawrence. American Journal of Science (ser. 3) 7: 210-219.

Submitted on 3 March 2009; accepted on 16 June 2009. 